\title{
Experimental and numerical analysis on the responses of slope under rainfall
}

\author{
X. B. Lu $\cdot$ T. L. Ye $\cdot$ X. H. Zhang $\cdot$ P. Cui $\cdot$ K. H. Hu
}

Received: 17 January 2012/Accepted: 29 June 2012/Published online: 12 July 2012

(C) Springer Science+Business Media B.V. 2012

\begin{abstract}
Rainfall is an important factor to trigger the slope failure such as landslides and debris flows. First, the relationship between rainfall duration with the initiation of debris flow and rainfall intensity was mainly studied by the series tests in a box model. Then, the rainfall induced responses of slopes and the initiation of slope failure were simulated by using the software FLAC2D based on the soil parameters in Weijia Gully, Beichuan County, Sichuan Province. The effects of the slope angle, rainfall intensity, soil parameters on the development of the stress, and pore pressure in the soil of the slope were analyzed. It indicates that largest displacements in the slope are mainly located near the toe. With the increase of the rainfall intensity, the effective stress in the slope decreases and the displacement increases.
\end{abstract}

Keywords Debris flow $\cdot$ Landslide Initiation of debris flow $\cdot$ Rainfall

\section{Introduction}

Landslide and debris flow distribute broadly in nature and threaten both lives and properties worldwide especially in regions of residual soils subject to heavy rainfall (Chen et al. 2006; Collins and Znidarcic 1999). Slope failure may develop due to human activities such as loading on the slope or excavating of the toe for construction purposes and then occur simply due to rainfall infiltrating (Anderson and Sitar 1995; Iverson et al. 2000; Cui et al. 2000).

Although many studies on the initiation of landslide and debris flow have been carried out (Aleotro 2004; Iverson 1992; Iverson et al. 1997), there are still many unknowns required to be explored. For an example, how does the pore pressure develop in the slope

X. B. Lu (ه) • T. L. Ye · X. H. Zhang

Institute of Mechanics, Chinese Academy of Science, Beijing 100084, China

e-mail: xblu@imech.ac.cn

P. Cui · K. H. Hu

Institute of Mountain Hazards and Environment, Chinese Academy of Science,

Chengdu 610041, China 
during and after a rainfall? Which is the most sensitive factor to the initiation of the slope failure? Some experiments and in situ measurements were used to study the initiation of landslide or debris flow in the previous studies (Cui 1992a, b; Reid et al. 1997), while numerical simulations were few processed. Numerical methods have the advantage to simulate the distribution of stresses, displacement, and pore pressure in a slope that could not be obtained fully from experiments. Furthermore, numerical simulations can conduct some special cases easily. For an example, the erosion and re-deposition of the fine grains that play an important role in the initiation of slope failures can be simulated easily (Cui et al. 2009; Lu and Zheng 2006; Lu and Cui 2010; Lu et al. 2010a).

Seepage and surface flow due to a rainfall obviously change the distribution of the soil suction stress, moisture et al., and then alter the stresses and the deformation of a slope (Lu and Likos 2006). The magnitude and dynamics of suction stress in sandy soils are sufficient to vary the factor of safety to cause failures near the ground surface (Lu and Godt 2008; Godt et al. 2009). Meanwhile, changes of the stress, suction force, and deformation can alter the seepage process because the hydraulic properties such as the porosity, permeability, and water storage capacity are affected. Hence, the seepage and stress-deformation process are coupled (Lu et al. 2010b; Zhang et al. 2005, 2011). Duration is an important parameter to forecast the initiation of landslide and debris flow, particularly for a real-time monitoring system (Chen et al. 2005; Ye et al. 2012).

So, the objective of this paper is to investigate the initiation of debris flow. First, the relationship between rainfall duration with the initiation of debris flow and rainfall intensity is explored experimentally; then, responses of the stresses, pore pressure in a slope under rainfall, are analyzed numerically.

\section{The main geological and hydrological characteristics in Beichuan}

Weijia Gully is located at the Renjiaping Village, Beichuan County, Sichuan Province. The geographical coordinates of the estuary are $104^{\circ} 26^{\prime} 27^{\prime \prime} \mathrm{E}, 31^{\circ} 48^{\prime} 48^{\prime \prime} \mathrm{N}$. The altitude of the starting point of debris flow and the estuary is 1,760 and $700 \mathrm{~m}$, respectively. The drainage area above the estuary is $1.54 \mathrm{~km}^{2}$. The main trench is $2.3 \mathrm{~km}$, and there is water flow circulation every year. This gully is near the main fracture of the 5.12 Large Earthquake in 2008, Wenchuan. Thus, the sediments in this area were severe broken and easy to be instability when disturbed. Two tributary gullies flow into Weijia Gully. The average width of the gully is $3-5 \mathrm{~m}$. The slope angle at the two sides of the gully is between $27^{\circ}$ and $45^{\circ}$. The vegetation coverage is 50-60\% (Tang and Liang 2008).

The outcrop stratum in the drainage area is mainly composed of the lower Cambrian series Qingping lark sandy shale, siltstone, thin-bedded sandy stone. This area suffers subtropical moist monsoon climate and abundant of rainstorms. Mean annual temperature is $15.6{ }^{\circ} \mathrm{C}$. The average annual rainfall was $1,399.1 \mathrm{~mm}$, and the maximum yearly rainfall was $2,340 \mathrm{~mm}$ in 1967 . The historical maximum daily rainfall intensity is $301 \mathrm{~mm} / \mathrm{day}$, and the maximum hourly rainfall intensity is $62 \mathrm{~mm} / \mathrm{h}$. Seventy-four percentage of the whole year rainfall is concentrated in from June to September. In September 23th, 2008, the rainfall intensity was $173.8 \mathrm{~mm} /$ day, and the maximum rainfall intensity was $61 \mathrm{~mm} / \mathrm{h}$ (Tang and Tie 2009). The large rainfall intensity is the key reason to lead to the initiation of debris flow. 


\section{The properties of in situ soils}

The in situ soils in the Weijia gully in Beichuan (Beichuan soils) County were used in experiments. The grain sizes of the soils are widely distributed as shown in Fig. 1. The dry density is $1.58 \mathrm{~g} / \mathrm{cm}^{3}$, and the saturation density is $2.0 \mathrm{~g} / \mathrm{cm}^{3}$.

The static stress-strain curves and Mohr circles of the saturated soils with grain diameters less than $2 \mathrm{~mm}$ in Weijia Gully were obtained by triaxial compression tests. There was no peak in stress-strain curves. The internal friction angle and the cohesion were measured as $22.2^{\circ}$ and $6 \mathrm{kPa}$, respectively (Fig. 2). These data are smaller than that of soils containing larger grains. Thus, in numerical simulation, the data were obtained by larger triaxial tests in literature (Zhang et al. 2010) (Shown in Table 1).

Fig. 1 Grain series curves for Beichuan soils. a Grain series with grain diameter ranging $0-10 \mathrm{~mm}$. b Grain series with grain diameter ranging $0-2 \mathrm{~mm}$ (a)

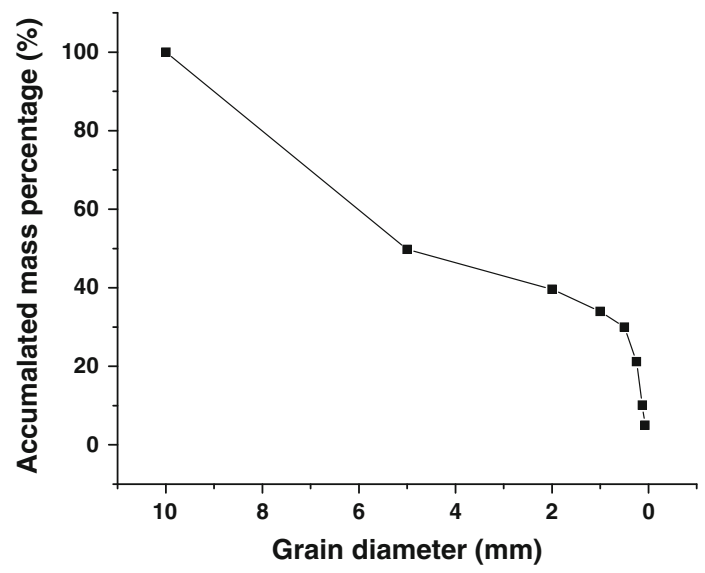

(b)

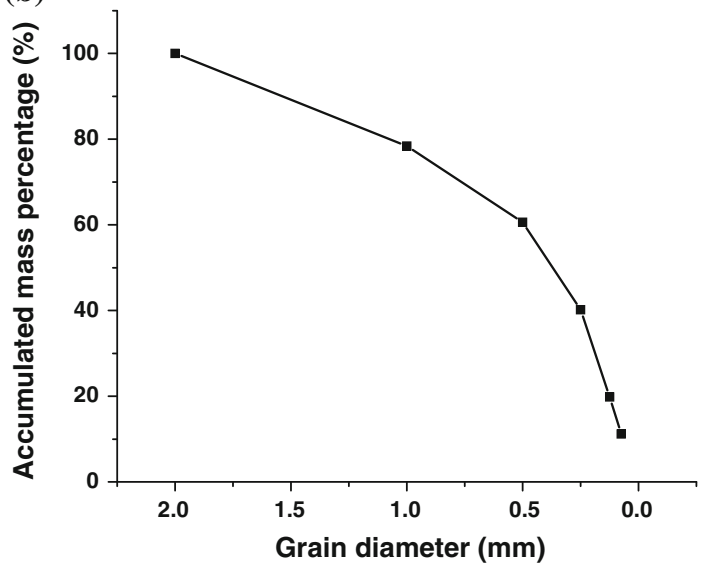


Fig. 2 Results of tri-axial tests. a Static stress-strain curves under different confined pressures. b Mohr circles and parameters of strength
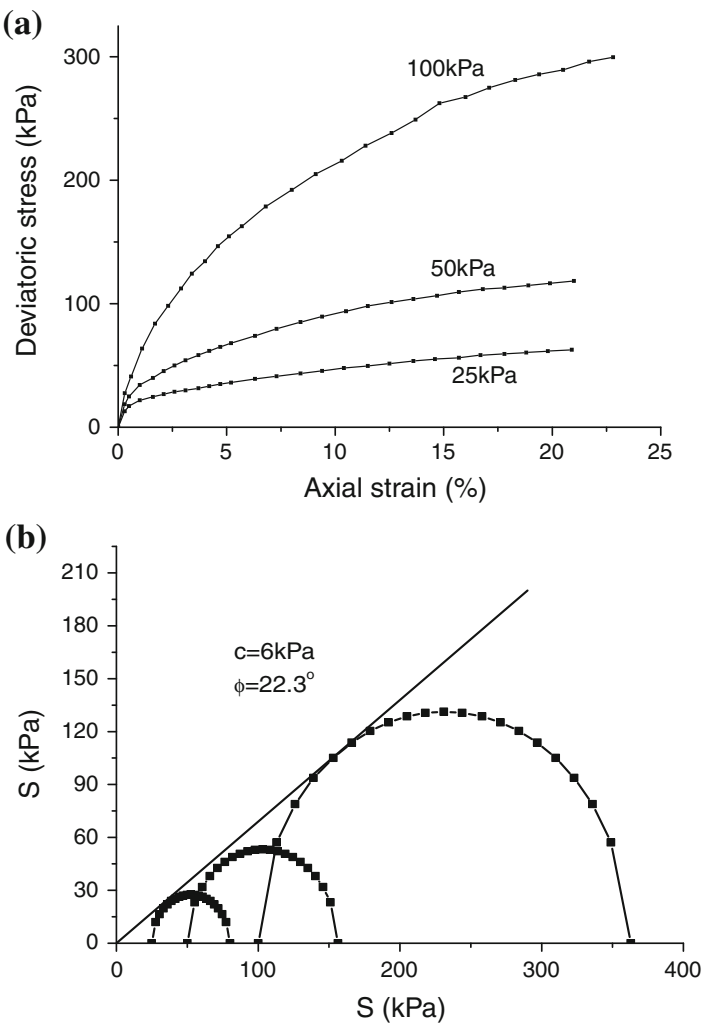

Table 1 Mechanical parameters of the slope

\begin{tabular}{llllll}
\hline $\begin{array}{l}\text { Dry density } \\
\left(\mathrm{kg} / \mathrm{m}^{3}\right)\end{array}$ & $\begin{array}{l}\text { Permeability } \\
(\mathrm{cm} / \mathrm{s})\end{array}$ & $\begin{array}{l}\text { Young's modulus } \\
(\mathrm{MPa})\end{array}$ & $\begin{array}{l}\text { Cohesion } \\
(\mathrm{kPa})\end{array}$ & $\begin{array}{l}\text { Internal friction } \\
\text { angle }\left({ }^{\circ}\right)\end{array}$ & $\begin{array}{l}\text { Poisson's } \\
\text { ratio }\end{array}$ \\
\hline 2,000 & $1.0 \times 10^{-4}$ & 6.2 & 20 & 30 & 0.22 \\
\hline
\end{tabular}

\section{Model experiments}

\subsection{Preparing of experiments}

The sample of the soil slope was prepared as a trapezia with a size of top length $\times$ bottom length $\times$ width $\times$ thickness $=35 \mathrm{~cm} \times 52 \mathrm{~cm} \times 21 \mathrm{~cm} \times 10 \mathrm{~cm}$. The slope angles in experiments were set as $27^{\circ}, 30^{\circ}, 32^{\circ}$, and $33^{\circ}$ according to the in situ conditions. Six sprayers were placed along a water pipe at intervals of $10 \mathrm{~cm}$ and $44 \mathrm{~cm}$ vertically over the soil layer surface. The rainfall intensity was relatively uniform at this set-up by repeated tests (Fig. 3). The rainfall intensity was controlled by a flow-meter. Some water was sprayed on the soil sample to make the soil with certain saturation after deposited. For each slope angle, 5-6 kinds of rainfall intensities were adopted ranging from 0.7 to $3.2 \mathrm{~mm} / \mathrm{min}$ in experiments. During the experiments, the displacements of the soils, seepage, and surface flow were measured, and the rainfall duration for debris flow to occur was 
recorded. The initial density is $1.58 \mathrm{~g} / \mathrm{cm}^{3}$ containing the water content of $4 \%$. When a large block of soil layer slid initially, we regarded the slope failure occured.

\subsection{Results of model experiments}

Little settlement was observed during rainfalls. No surface flow occurred even under strong rainfalls. It indicates that the in situ soil layer had such large permeability that rainfall could fully percolate into and flow through. For any slope angle, the rainfall duration corresponding to the initiation of debris flow decreased with the increase of the rainfall intensity (Fig. 4). A critical rainfall intensity existed.

Generally, the slope fails only after the rainfall percolates into the slope with some depth and saturates the soil to high water content. The physical and geometrical properties of the slope soil change with the duration of the water seepage, and the pore water pressure increases with water flow and gathering. Then slope failures initiate at critical rainfall intensity.

The fine grains play an important role in the slope failure with wide grain sizes as the soil in Weijia Gully. The fine grains reduce the friction and cohesion acting as a kind of lubricant after sucking the rain water and then promotes the initiation of slope failures. From Fig. 5, it shows that the fine grains adhere to large grains as soil membrane after water sucking. This causes the cohesive force among large grains decrease and even disappear. When appending more fine grains, the critical rainfall duration becomes shorter under the same rainfall intensities and slope angles (Fig. 6).

\section{Numerical simulation}

\subsection{Numerical model}

The software FLAC2D was used to simulate the responses of a slope under rainfall. The parameters used in numerical simulations were the same as that in experiments.

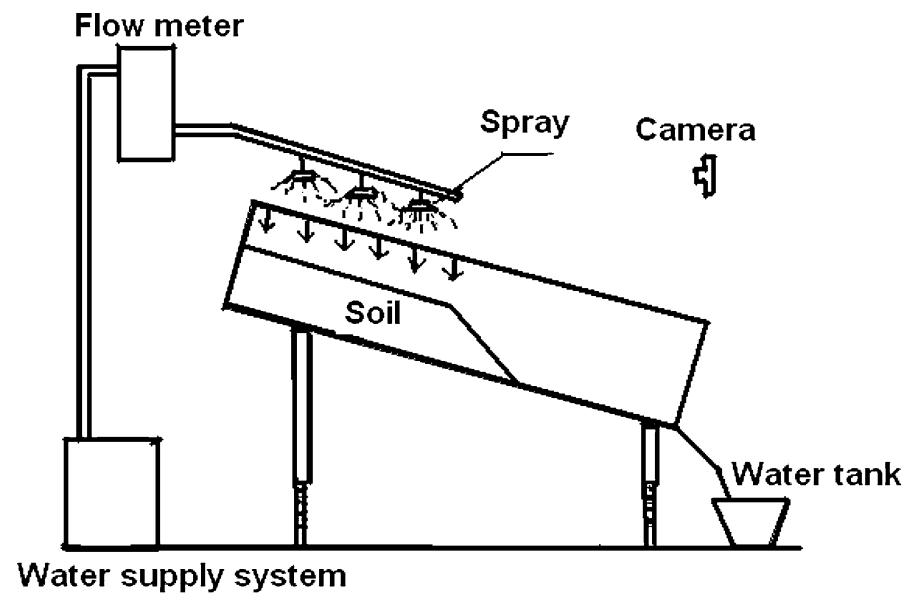

Fig. 3 Sketch of the model 
Fig. 4 Rainfall intensityrainfall duration for Wenchuan soils

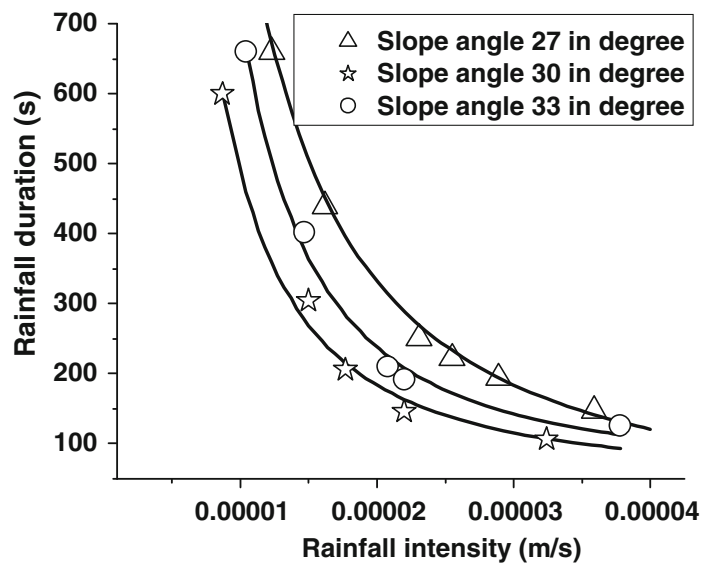

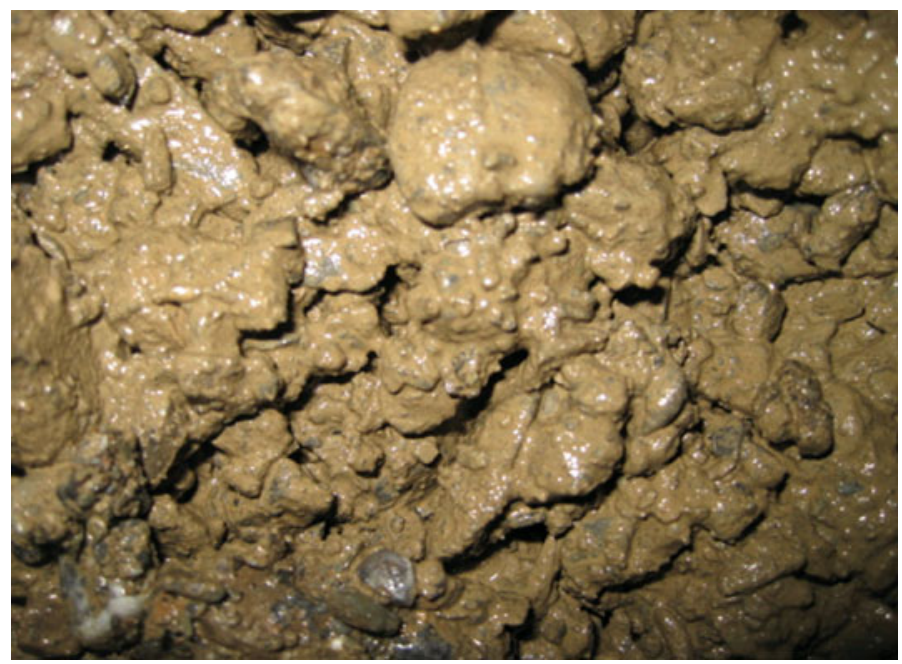

Fig. 5 Photo of a local section of the sliding surface

Fig. 6 Rainfall intensityrainfall duration curves of the soil in Weijia Gully and the soil adding fine grains

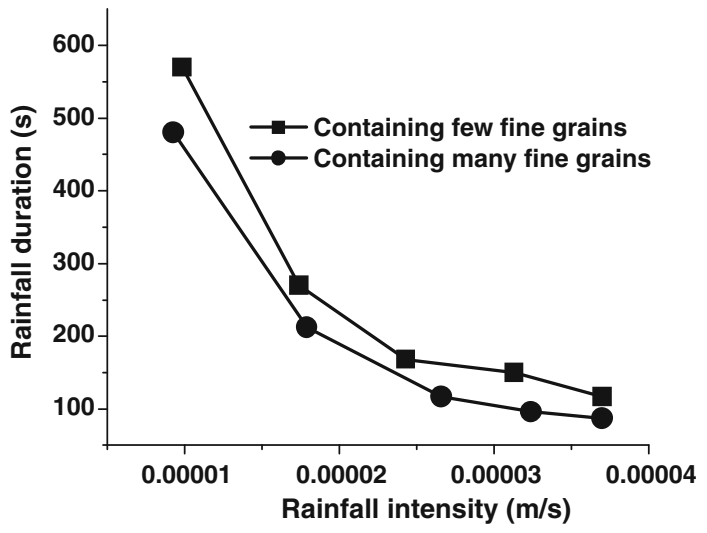


The bottom was vertically fixed, the top was free, and the other boundaries were all normally fixed (Fig. 7). The height of the slope was $20 \mathrm{~cm}$, and the slope angles were $27^{\circ}$, $30^{\circ}$, and $33^{\circ}$, respectively. The Mohr-Column criterion was applied to describe the soil mechanical behavior of the slope. The Darcy Law described the seepage of the two phases (pore air and pore water). The mechanical parameters adopted in simulation are shown in Table 1.

The seepage equations for the pore water and the pore air are shown in the following (Fredlund and Rahardjo 1993):

$$
\begin{aligned}
& q_{i j}^{w}=-k_{i j}^{w} k_{r}^{w} \frac{\partial}{\partial x_{j}}\left(P_{w}-\rho_{w} g_{k} x_{k}\right) \\
& q_{i j}^{g}=-k_{i j}^{g} k_{r}^{g} \frac{\partial}{\partial x_{j}}\left(P_{g}-\rho_{g} g_{k} x_{k}\right)
\end{aligned}
$$

The strength criterion is expressed as (Fredlund and Rahardjo 1993):

$$
\tau_{f}=\left(\sigma-P_{a}\right) \tan \phi+S_{w}\left(P_{a}-P_{w}\right) \tan \phi+C
$$

The capillary force is satisfied with the following equation:

$$
P_{c}=P_{g}-P_{w}
$$

and

$$
P_{c}=P_{0}\left[S_{e}^{-1 / a}-1\right]^{1-a}
$$

The relative permeability of the pore water is expressed as (Brooks and Corey 1964, 1966):

$$
k_{r}^{w}=S_{e}^{b}\left[1-\left(1-S_{e}^{1 / a}\right)^{a}\right]^{2}
$$

The relative permeability of pore gas is:

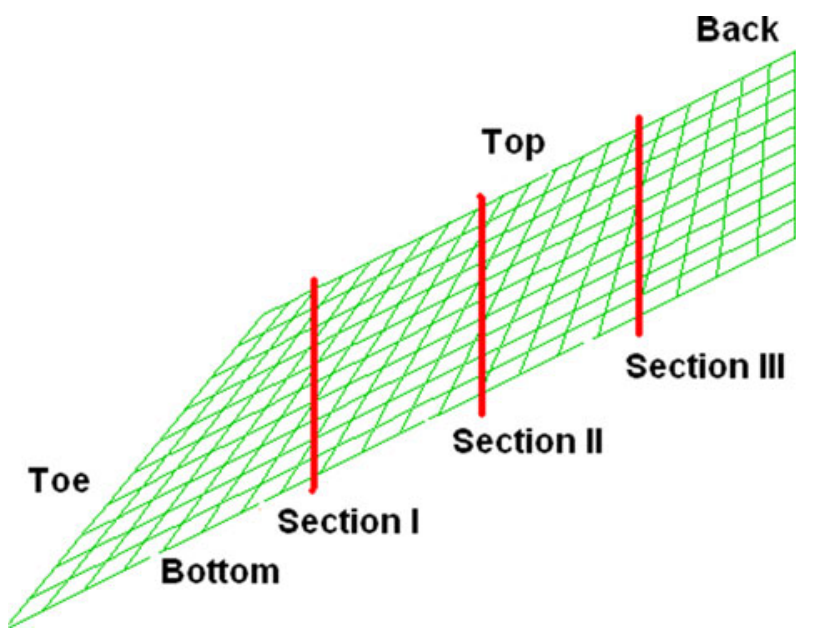

Fig. 7 Finite difference grid for numerical simulation and experimental results 


$$
k_{r}^{g}=\left(1-S_{e}^{b}\right)^{c}\left(1-S_{e}^{1 / a}\right)^{2 a}
$$

in which $S_{e}$ is (Corey 1954):

$$
S_{e}=\frac{S_{w}-S_{r}^{w}}{1-S_{r}^{w}}
$$

$q_{i j}^{w}, q_{i j}^{g}$ are the flow rate of the water and the air, $k_{i j}^{w}$ the saturated permeability, $k_{r}^{w}$ the relative permeability of water, $k_{r}^{g}$ the relative permeability of air, $P_{w}$ the pore water pressure, $P_{g}$ pore gas pressure, $\rho_{w}$ density of water, $\rho_{g}$ density of gas, $g_{k}, x_{k}$ the gravity acceleration and position, when their directions are different, their product equals zero, $\tau_{f}$ the strength, $\sigma$ the total stress, $S_{w}$ saturation of water, $\phi$ the internal friction angle, $C$ the cohesion, $S_{r}^{w}$ the saturation of water.

Table 2 Rainfall intensity adopted in the numerical simulation

\begin{tabular}{llllll}
\hline Slope angle $\left(^{\circ}\right)$ & \multicolumn{5}{l}{} \\
\hline 27 & $1.0 \times 10^{-5}$ & $2.0 \times 10^{-5}$ & $3.0 \times 10^{-5}$ & $4.0 \times 10^{-5}$ & $5.0 \times 10^{-5}$ \\
30 & $1.0 \times 10^{-5}$ & $2.0 \times 10^{-5}$ & $3.0 \times 10^{-5}$ & $4.0 \times 10^{-5}$ & $5.0 \times 10^{-5}$ \\
33 & $1.0 \times 10^{-5}$ & $2.0 \times 10^{-5}$ & $3.0 \times 10^{-5}$ & $4.0 \times 10^{-5}$ & $5.0 \times 10^{-5}$ \\
\hline
\end{tabular}

(a)

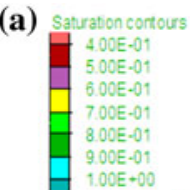

(c)

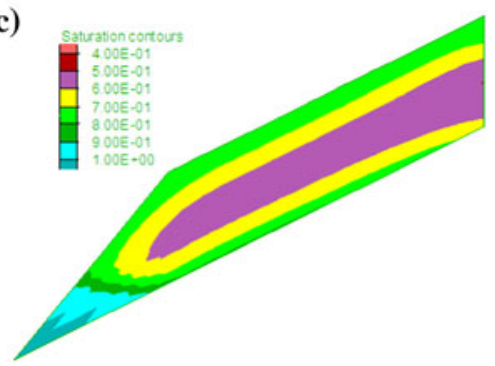

(b)

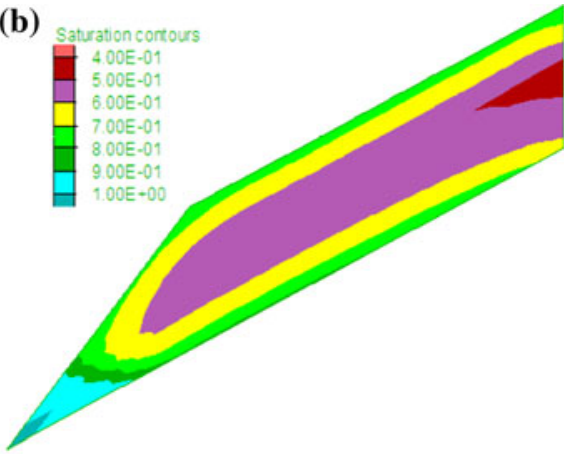

(d)

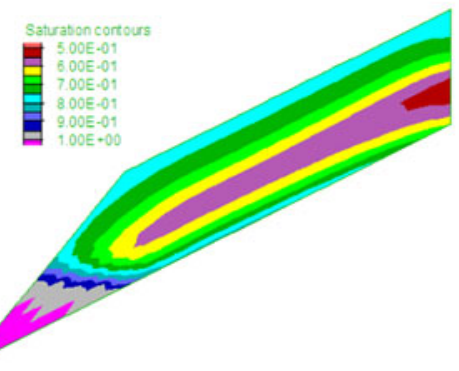

Fig. 8 Water saturation distribution under the rainfall intensity of $1 \times 10^{-5} \mathrm{~m} / \mathrm{s}$ (Unit of saturation is \%). a $t=100 \mathrm{~s}$. b $t=200 \mathrm{~s}$. c $t=300 \mathrm{~s} . \mathbf{d} t=400 \mathrm{~s}$ 


\subsection{Scheme of the numerical simulation}

The rainfall intensity, slope angle, soil density, soil strength, and permeability were mainly considered. The rainfall intensity ranged from $4 \times 10^{-6}$ to $5 \times 10^{-5} \mathrm{~m} / \mathrm{s}$ (Table 2). The finite difference grid of the slope for numerical simulations was shown in Fig. 7. Points A and $\mathrm{B}$ were used as the characteristic data.

\subsection{Numerical results and analysis}

\subsubsection{The development of the water saturation}

Figure 8 shows the nephograms of the water saturation in the slope when the rainfall durations are $100 \mathrm{~s}, 200 \mathrm{~s}, 300 \mathrm{~s}$, and $400 \mathrm{~s}$, respectively, and the rainfall intensity is $1 \times 10^{-5} \mathrm{~m} / \mathrm{s}$. The wetting front develops gradually from the surface to the interior of the slope in a nonlinear form. Water saturation near the surface and at the toe of the slope increases apparently in $100 \mathrm{~s}$. The wetting front arrives at about 1/2 depth of the slope when the rainfall lasts $400 \mathrm{~s}$. The pore water percolations from the surface to the bottom and from the upper part to the toe. Then, water saturation increases from the surface to the bottom and becomes larger at the surface and the bottom than that of other locations.

It is shown that the wetting front develops faster when the rainfall intensity increases to $5 \times 10^{-5} \mathrm{~m} / \mathrm{s}$ with a tendency similar to that of $1 \times 10^{-5} \mathrm{~m} / \mathrm{s}$ (Fig. 9). The wetting front is less than $1 / 4$ depth of the slope from the surface when the rainfall duration is $100 \mathrm{~s}$ and

(a)

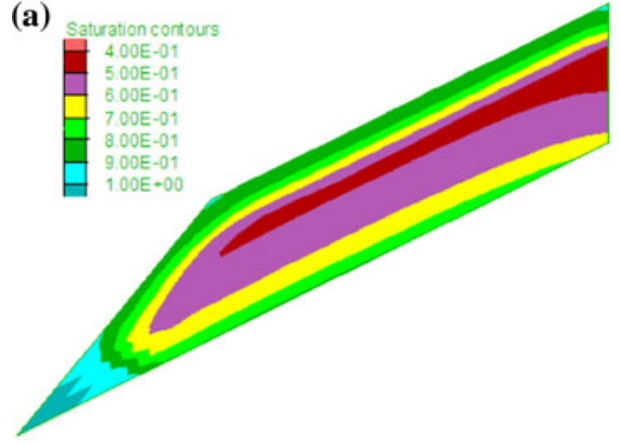

(c)

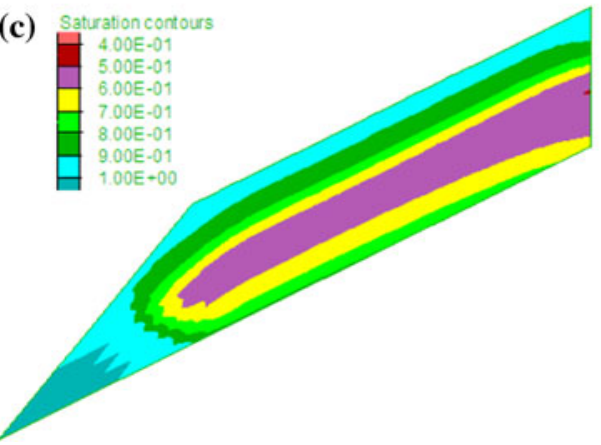

(b)

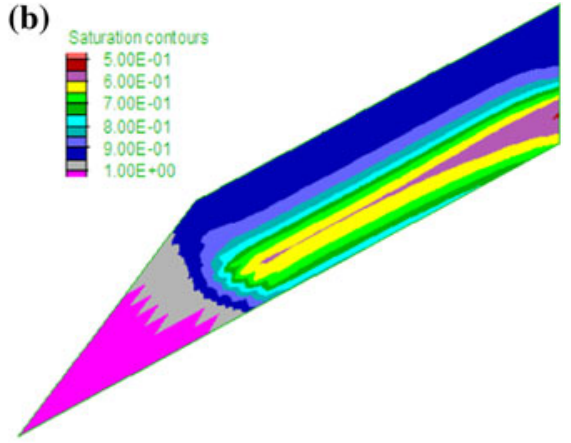

(d)

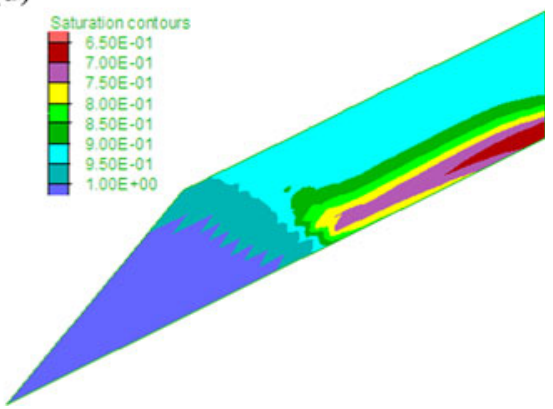

Fig. 9 Water saturation distribution under rainfall intensity of $5 \times 10^{-5} \mathrm{~m} / \mathrm{s}$ (Unit of saturation is \%). a $t=100 \mathrm{~s} . \mathbf{b} t=200 \mathrm{~s} . \mathbf{c} t=300 \mathrm{~s} . \mathbf{d} t=400 \mathrm{~s}$ 
reaches to 5/6 depth at $400 \mathrm{~s}$. The fully saturated area is larger than that under rainfall intensity of $1 \times 10^{-5} \mathrm{~m} / \mathrm{s}$. In this condition, runoff occurs, indicating that the water penetrated into soil layer is less than supplied by rainfall.

Figure 10 shows the changes of the water saturation with depth at the three sections of the slope. The largest water saturation locates at the surface, while the smallest water saturation locates at the middle. The reason may be the rainfall water permeates first at the surface and then decreases with depth. The seepage before rainfall causes the water saturation at the bottom larger than that at the middle. At any given time, the development of the pore water pressure at sections II and III is almost the same but different from section I (Fig. 10d).

The water saturation at the toe of the slope increases apparently, and the fully saturated area increases with time. Runoff occurs when the rainfall intensity reaches to certain extent. The wetting front develops into the interior of the slope gradually. The developing velocity of the wetting front increases with the increase of the rainfall intensity. The saturation near the surface increases faster and larger than that of the interior. The development of the water saturation at section I is different from sections II and III due to the seepage at the toe.

(a)

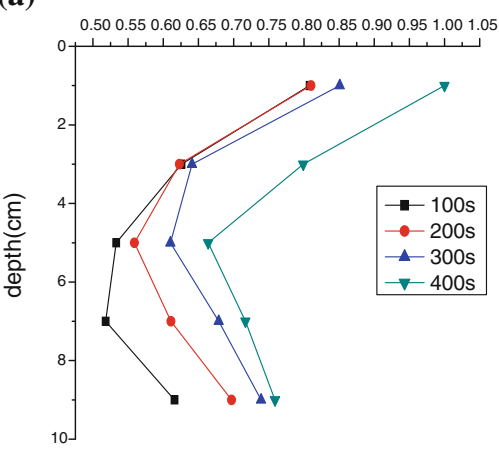

(c)
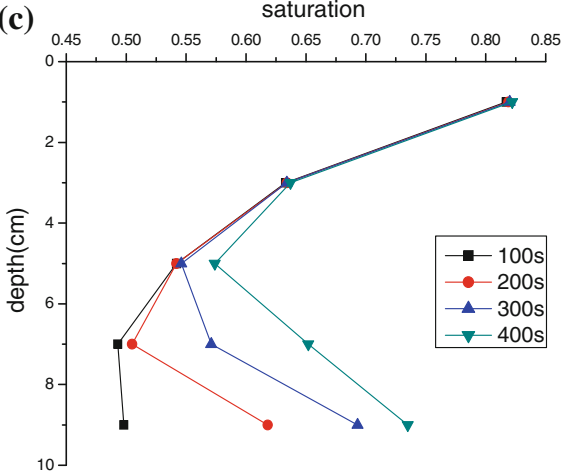

(b)

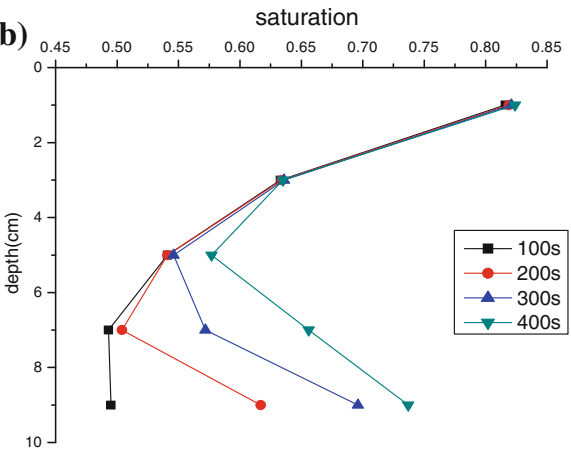

(d)

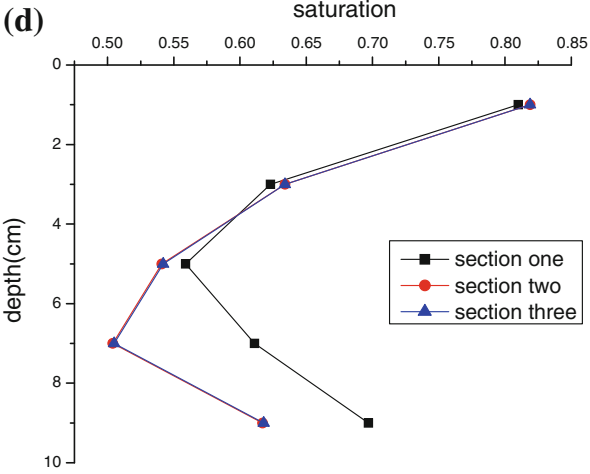

Fig. 10 Changes of the water saturation along depth. a Section I. b Section II. c Section III. d At rainfall duration of $200 \mathrm{~s}$ 

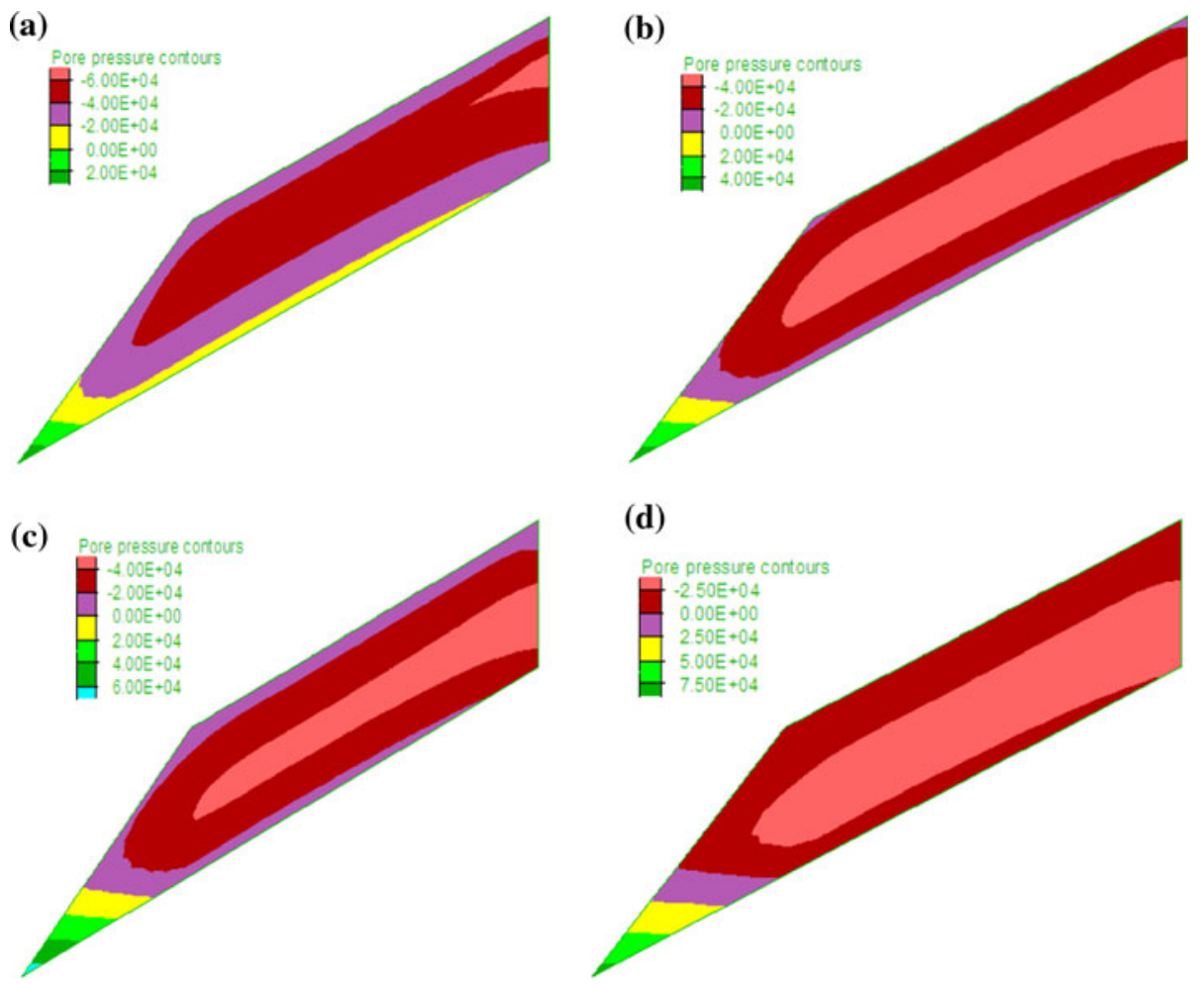

Fig. 11 Distribution of the pore water pressure under rainfall intensity of $1 \times 10^{-5} \mathrm{~m} / \mathrm{s}$ (Unit of pore pressure is $\mathrm{Pa}$ ). a $t=100 \mathrm{~s}$. b $t=200 \mathrm{~s}$. c $t=300 \mathrm{~s}$. d $t=400 \mathrm{~s}$

\subsubsection{Development of pore water pressure}

Figure 11 shows the distribution of the pore water pressure under the rainfall intensity of $1 \times 10^{-5} \mathrm{~m} / \mathrm{s}$ and the rainfall durations of $100 \mathrm{~s}, 200 \mathrm{~s}, 300 \mathrm{~s}, 400 \mathrm{~s}$, respectively. It can be seen that the pore water pressure near the toe of the slope increases remarkably with the rainfall. The affected area (the area that the rainfall percolates into) increases with time. The pore water pressure occurs first at the toe and then expand. At the rainfall duration of $400 \mathrm{~s}$, positive pore water pressure covers about a half of the whole area with a largest pore water pressure of $7.5 \times 10^{4} \mathrm{~Pa}$, while at $100 \mathrm{~s}$, only about $1 / 6$ area is covered with a largest pore water pressure of $2.0 \times 10^{4} \mathrm{~Pa}$. This indicates that the failure initiates more easily at the toe.

The distribution of the pore water pressure under the rainfall intensity of $5 \times 10^{-5} \mathrm{~m} / \mathrm{s}$ is similar to that of $1 \times 10^{-5} \mathrm{~m} / \mathrm{s}$. However, the pore water pressure increases faster but the area is larger. Under the rainfall intensity of $5 \times 10^{-5} \mathrm{~m} / \mathrm{s}$, all the areas are covered with positive pore water pressure while only $1 / 2$ under the rainfall intensity of $1 \times 10^{-5} \mathrm{~m} / \mathrm{s}$ at the duration of $400 \mathrm{~s}$. The high pore water pressure leads to more water percolation (Fig. 12).

The developing tendency of the pore water pressure is similar to that of the water saturation (Fig. 13) and almost the same at the sections I, II, and III (Fig. 13a-c). But at any given time, the value of the pore water pressures at sections II and III are almost the same but different from section I. 
(a)

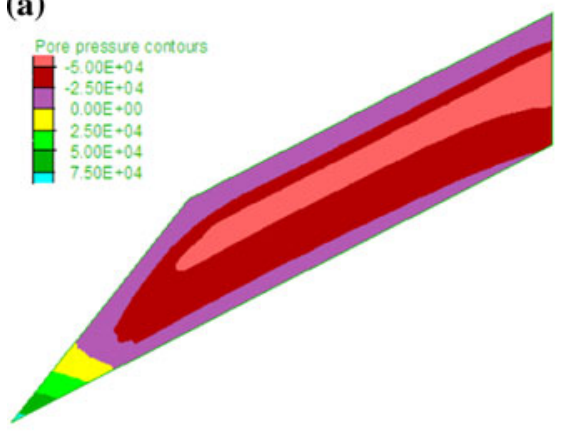

(c)

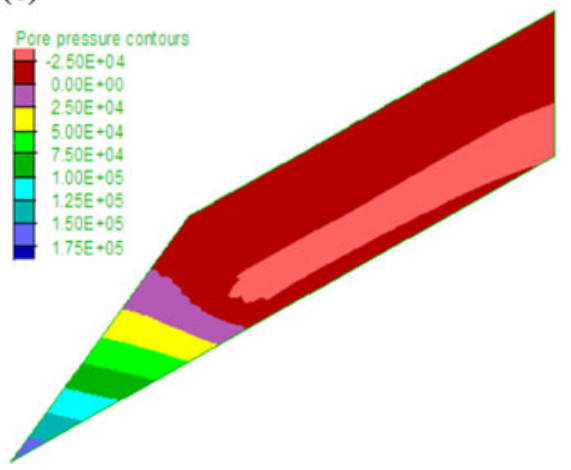

(b)

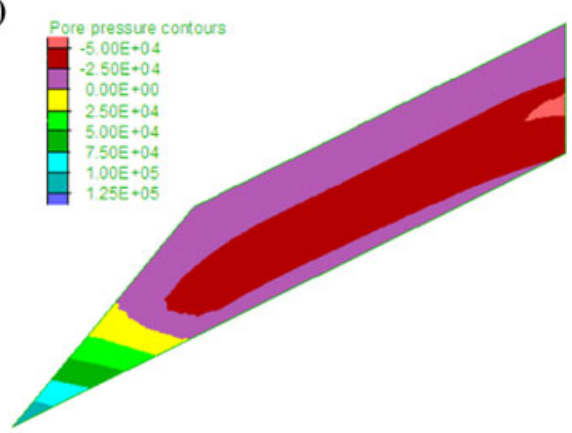

(d)

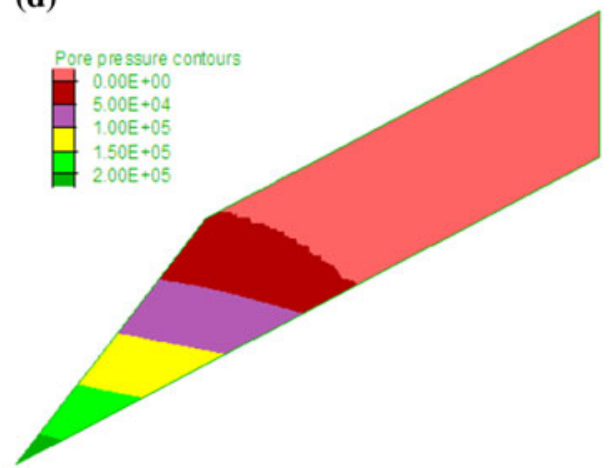

Fig. 12 Distribution of the pore water pressure under rainfall intensity of $5 \times 10^{-5} \mathrm{~m} / \mathrm{s}$ (Unit of pore pressure is Pa). a $t=100 \mathrm{~s}$. b $t=200 \mathrm{~s}$. c $t=300 \mathrm{~s}$. d $t=400 \mathrm{~s}$

Figure 14 shows the development of the water saturation and the pore water pressure under the rainfall intensity of $1 \times 10^{-5} \mathrm{~m} / \mathrm{s}$ at the section III. The water saturation and pore water pressure develop with time near the surface of the slope. At the location of $1 \mathrm{~cm}$ from the surface, the water saturation and the water pore pressure increase initially when the rainfall lasts $200 \mathrm{~s}$ and the saturation becomes $100 \%$ at last, while unchanged at the locations of $7 \mathrm{~cm}$ and $9 \mathrm{~cm}$ from the surface.

It can be concluded that the water saturation and the pore water pressure at the toe and the upper part increase faster than at the low part. Thus, the strength at these areas is lower, causing soils migrate from the upper part to the toe (Fig. 15).

\subsubsection{Comparison of experimental and numerical results}

For a verification, the numerical results are compared with the experimental results. The parameters in simulation are adopted according to experiments: The slope angle is $27^{\circ}$; soil parameters are shown in Table 1 . Generally, with the penetration of rain water, the displacement of the slope develops from slow to fast suddenly (Lu et al. 2011). The sudden change is thought as the initiation of slope failure in this paper. The relationship between the rainfall intensity and the rainfall duration is in agreement with the experimental results, and the numerical simulation is valid (Fig. 16). 
(a)

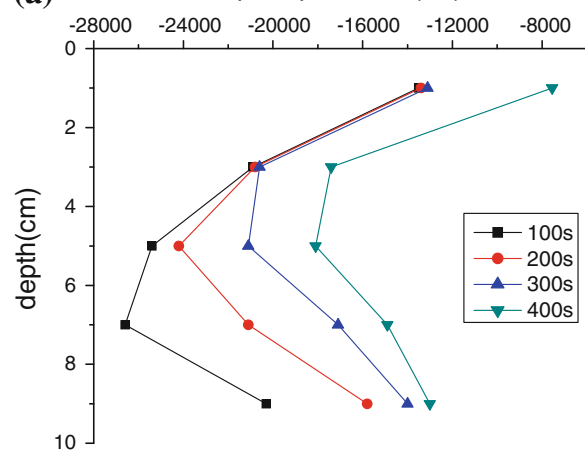

(c)

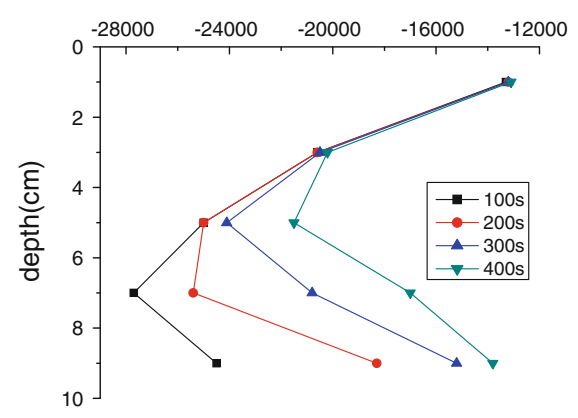

(b) pore pressure $(\mathrm{Pa})$

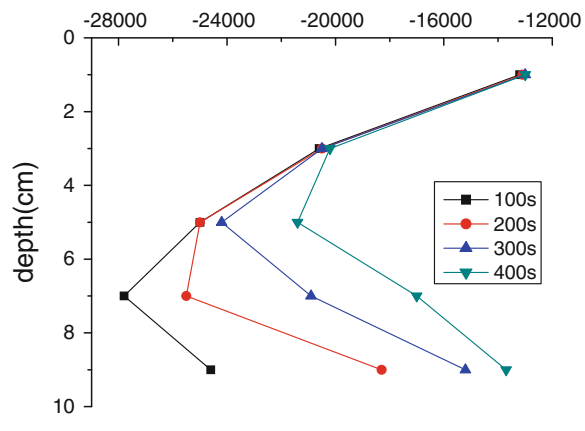

(d)

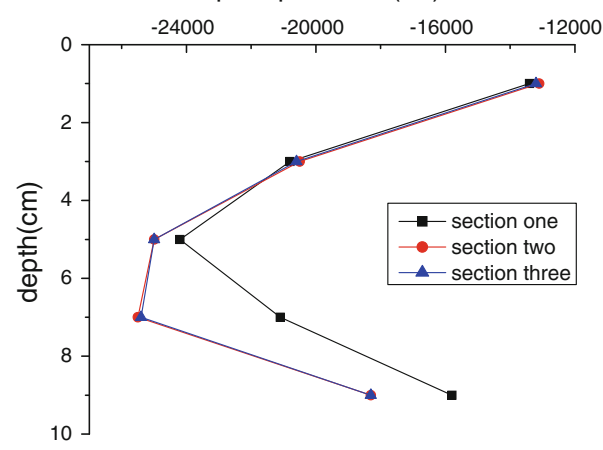

Fig. 13 Distribution of pore water pressure along depth. a Section I, b Section II. c Section III. d Section IV

\section{Conclusions}

The soil responses of the slope during rainfall were studied experimentally and numerically. By comparison between numerical simulation and experiments, they are in good agreements. The main conclusions are as follows:

1. The pore water pressure and water saturation in the slope increase with rainfall duration time and rise faster with rainfall intensity. Under the rainfall intensity of $1 \times 10^{-5} \mathrm{~m} / \mathrm{s}$, the wetting front arrives at about $1 / 2$ depth of the slope from the surface when the rainfall lasts $400 \mathrm{~s}$.

2. The largest pore water pressure and water saturation are located near the slope toe and the surface. The area with pore water pressure increases with the increase of rainfall intensity.

3. The rainfall duration corresponding to the initiation of debris flow decreases with the increase of the rainfall intensity and critical rainfall intensity exists to determine the possible occurrence of landslide and debris flow. The fine grains play an important role in the slope failure with wide grain sizes because they become the lubricant with the increase of moisture. 
Fig. 14 Development of pore pressure and water saturation with time at section III. a Water saturation degree versus time. b Pore pressure versus time
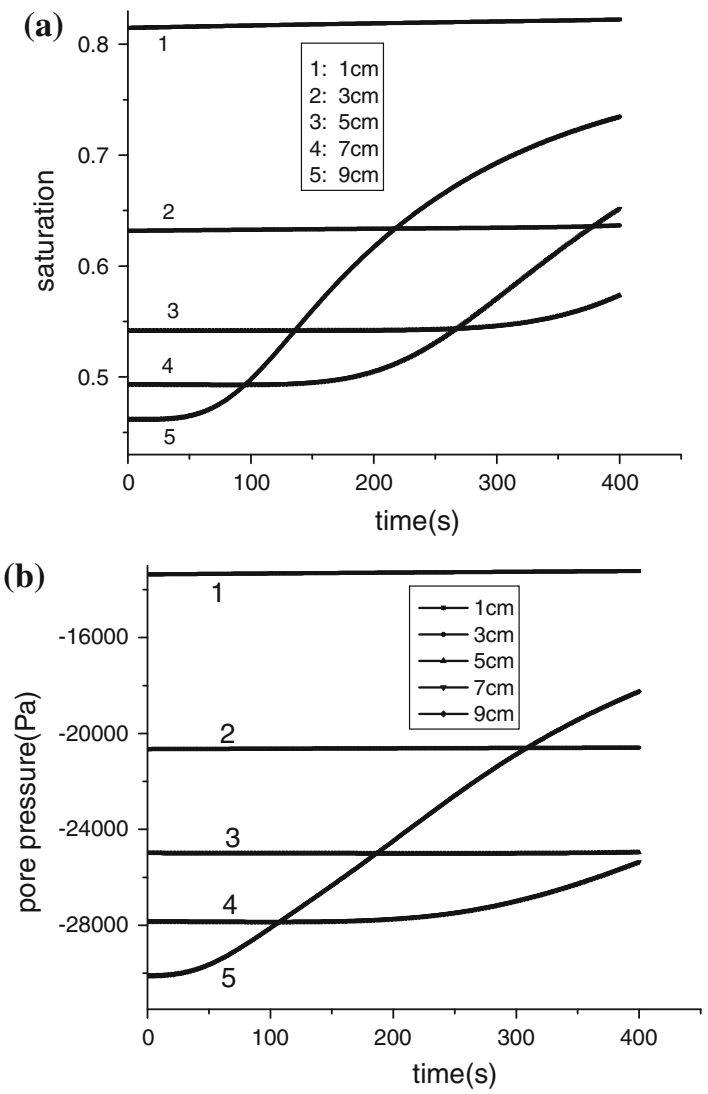

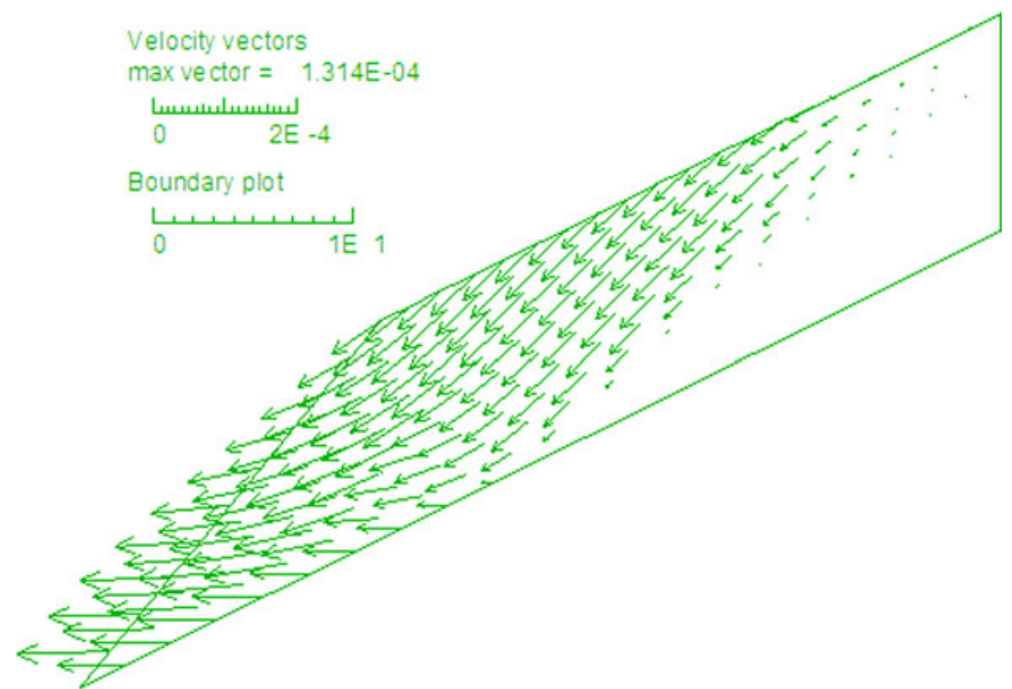

Fig. 15 Total velocity vector distribution of the soils under rainfall intensity $5 \times 10^{-5} \mathrm{~m} / \mathrm{s}$ and slope angle $27^{\circ}$ in degree 
Fig. 16 Comparison of the numerical and experimental results

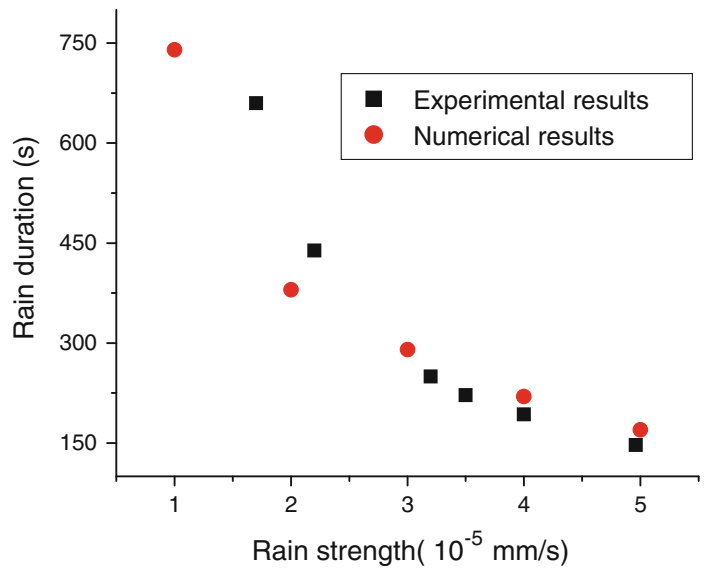

Acknowledgments This paper is supported by National Basic Research Program of China "Activity characteristics and formation rules of secondary mountain hazard of earthquake"(No. 2008CB425802) and Key Program of Chinese Academy of Sciences (No.KZCX2-YW-302-02).

\section{References}

Aleotro P (2004) A warning system for rainfall-induced shallow failures. Eng Geol 73:247-265

Anderson SA, Sitar N (1995) Analysis of rainfall-induced debris flow. J Geotech Eng 121(7):544-552

Brooks RH, Corey AT (1964) Hydraulic properties of porous media. Civil Engineering Dept., Colorado State University, Hydrological Paper 3

Brooks RH, Corey AT (1966) Properties of porous media affecting fluid flow. J Irrigation Drainage Div ASCE 92:61-88

Chen CY, Chen TC, Yu FC, Yu WH, Tseng CC (2005) Rainfall duration and debris-flow initiated studies for real-time monitoring. Environ Geol 47:715-724

Chen XQ, Cui P, Feng ZL, Chen J, Li Y (2006) Artificial rainfall experimental study on landslide translation to debris flow. Chin J Rock Mech Eng 25(1):106-116 (in Chinese)

Collins BD, Znidarcic D (1999) Stability analyses of rainfall induced landslide. ASCE J Geotech Geoenviron Eng 130(4):362-372

Corey AT (1954) The interrelation between gas and oil relative permeabilities. Prod Mon 19(1):38-41

Cui P (1992a) Study on condition and mechanisms of debris flow initiation by means of experiment. Chin Sci Bull 37(9):759-763 (in Chinese)

Cui P (1992b) A study on theoretical methods of forecasting debris flow. Interpraevent 1992-Bern 5:307-321

Cui P, Liu SJ, Tan WP (2000) Progress of debris flow forecast in China. J Nat Disasters 9(2):10-15 (in Chinese)

Cui P, Ge YG, Zhuang JQ, Wang DJ (2009) Soil evolution features of debris flow waste-shoal land. J Mt Sci 6(2):181-188

Fredlund DG, Rahardjo H (1993) Soil mechanics for unsaturated soils. Wiley, New York

Godt JW, Baum R, Lu N (2009) Can landslides occur under unsaturated soil conditions? Geophys Res Lett 36:L02403

Iverson RM (1992) The physics of debris flows. Rev Geophys 35(3):245-296

Iverson RM, Reid ME, LaHusen RG (1997) Debris-flow mobilization from landslides. Annu Rev Earth Planet Sci 25:85-138

Iverson RM, Reid ME, Iverson NR, LuHusen RG, Logan M, Mann JE, Brien DL (2000) Acute sensitivity of landslide rates to initial soil porosity. Science 290(5491):513-516

Lu XB, Cui P (2010) On the study of water film in saturated soils. Int J Sediment Res 25:221-232

Lu N, Godt J (2008) Infinite slope stability analysis under steady unsaturated seepage conditions. Water Resour Res 44:W11404 
Lu N, Likos WJ (2006) Suction stress characteristic curve for unsaturated soils. J Geotech Geoenviron Eng 132(2):131-142

Lu XB, Zheng ZM (2006) Formation of water film in saturated sand. Acta Mech Sinica 22:377-383

Lu XB, Cui P, Hu KH, Zhang XH (2010a) The initiation and development of water film by seepage. J Mt Sci 7:361-366

Lu N, Godt J, Wu D (2010b) A closed-form equation for effective stress in variably saturated soil. Water Resour Res 46:W05515

Lu XB, Ye TL, Cui P, Hu KH, Chen XQ (2011) Numerical investigation on the initiation mechanism of debris-flow under rainfall. J Mt Sci 8:619-628

Reid ME, LaHusen RG, Iverson RM (1997) Debris-flow initiation experiments using diverse hydrologic triggers. In: Chen C-L (ed) Debris-flow hazards mitigation: mechanics, prediction, and assessment. ASCE, pp 1-11

Tang C, Liang JT (2008) Characteristics of debris flows in Beichuan epicenter of the Wenchuan earthquake triggered by rainstorm on September 24, 2008. J Eng Geol 16(6):751-758 (in Chinese)

Tang C, Tie YB (2009) Reconnaissance and analysis on the Rainstorm induced debris flow in Weijiagou valley of Beichuan City after the Wenchuan earthquake. J Mt Sci 27(5):625-630 (in Chinese)

Ye TL, Lu XB, Cui P, Hu KH (2012) Experimental study of the initiation of debris flow in Beichuan, Sichuan Province. J Mt Sci (being printed, in Chinese)

Zhang LL, Zhang LM, Tang WH (2005) Rainfall-induced slope failure considering variability of soil properties. Geotechnique 55(2):183-188

Zhuang JQ, Cui P, Hu KH, Chen XQ, Ge YG (2010). Characteristics of earthquake-triggered landslides and post-earthquake debris flow in Beichuan County. J Mt Sci 7(3):246-254

Zhang LL, Zhang LM, Zhang J, Tang WH (2011) Stability analysis of rainfall-induced slope failure: a review. Geotech Eng 164(GE5):299-315 